\title{
Effective Removal of Methyl blue and Crystal Violet Dyes Using Improved Polysulfone / ZIF-8 Nanocomposite Ultrafilltration Membrane
}

\author{
Mohamed E.A. Ali 1,*(D), Aly H. Atta ${ }^{2}$, Mohamed Medhat 2,3,*iD, Ahmed Shahat 2,*iD, Shaimaa K. \\ Mohamed $^{2}$ (D)
}

1 Egyptian desalination research Center of excellence (EDRC) \& Hydrogeochemistry Department, Desert Research Center, Cairo, 11753, Egypt; m7983ali@gmail.com (M.E.A.A.);

2 Chemistry Department, Faculty of Science, Suez University, Suez 43518, Egypt; melsowefy @ gmail.com (M.M.); ashahat@aucegypt.edu (A.S.);

3 Quality Control Department, Direct Reduction Plant, Ezz Steel, Suez 43552, Egypt; melsowefy@gmail.com (M.M.);

* Correspondence: m7983ali@gmail.com (M.E.A.A.); ashahat@aucegypt.edu (A.S.); melsowefy@gmail.com(M.M)

Received: 23.09.2021; Revised: 5.11.2021; Accepted: 8.11.2021; Published: 4.12.2021

\begin{abstract}
Zeolitic Imidazole framework 8 (ZIF-8) was successfully prepared in an aqueous medium and then dissolved with concentrations ranging from $0.5 \%$ to $5 \%$ in polysulfone (PSF) to prepare an ultrafiltration membrane. ZIF-8 nanosized material uniformly distributed in the PSF membrane ultrafiltration membrane was prepared in a polar solvent of N,N'-dimethyl formamide (DMF) by phase inversion procedure. Significantly, ZIF-8 enhanced the membrane flux from $50.42 \mathrm{~L} / \mathrm{m} 2 . \mathrm{h}$ (PSF) to $83.65 \mathrm{~L} / \mathrm{m} 2 . \mathrm{h}$ at $100 \mathrm{Kpa}$, and the rejection of methyl blue and crystal violet dyes up to $95.1 \%$ and 89.65 $\%$, respectively compared to the PSF membrane without ZIF-8, 41.08\%, 46.32\%. Wavelength dispersive X-ray fluorescence (WD-XRF), X-ray Diffraction (XRD), scanning electron microscopy (SEM), contact angle, and dead-end filtration experiment were carried out to characterize the morphology and performance of the prepared ZIF-8 and membranes. The hydrophilicity of the membrane was determined by a contact angle test between water and membrane. SEM was used to study the surface and the cross-sectional morphologies.
\end{abstract}

Keywords: polysulfone; ZIF-8; phase inversion; ultrafiltration, membrane; crystal violet; methyl blue. (C) 2021 by the authors. This article is an open-access article distributed under the terms and conditions of the Creative Commons Attribution (CC BY) license (https://creativecommons.org/licenses/by/4.0/).

\section{Introduction}

Water became essential in various fields, such as domestic use, electricity generation, tourism, leisure, manufacturing, and agriculture. However, the water's most crucial usage in drinking water is increasing quickly. This high demand encouraged many scientists and investors to focus on water treatment.

Many industries incorporate dyes, including papers, paints, and textiles industries. Unfortunately, the wastewater released from those industries contains many organic compounds and hazardous dyes which harmfully affect the environment. In addition, any small quantity of dye in water could affect aquatic life by blocking the sunlight beams. To avoid all those drawbacks, this colored wastewater must be treated appropriately before discarding it.

It was challenging to handle a dye effluent adequately due to its complexity. Many decolorization procedures have been documented in recent decades, including physical [1], chemical, and biological processes [2]. 
Within water treatment technologies, membrane processes are more favored, as they are cost-effective and quickly purify the water, highly selective, and flexible to be combined with other procedures. Polymer membranes are the famously used technique, but their hydrophobic surface is the major limitation that affects the permeability and rejection of the membrane [3-12]. In order to avoid these drawbacks, different organic and inorganic materials have been applied [13-19]. Metal ions and organic ligands are connected, forming one of the highest porous materials, the Metal-Organic Framework (MOFs), which attracts many researchers nowadays [20-22]. It has a very high surface area and pore structure. Its different chemical compositions allow it to be utilized in various applications [23, 24] with high selectivity according to its design and chemical composition. The zeolitic imidazole framework (ZIF-8) is a famous MOF used in diverse applications because of its exceptional chemical and thermal stability [25, 26]. ZIFs have high porosity and unique surface structure, making them more favorable than zeolites in many applications [27-33].

ZIF-8 was prepared and utilized to acquire different concentrations in PVDF membranes [34]. Those membranes were tested for permeability and rejection Rose Bengal (RB) from ethanol and isopropanol (IPA). The membrane containing $25 \%$ of ZIF-8 obtained the best rejection for $(\mathrm{RB})$.

A fabricated uniform ZIF-8/ polymer hybrid membrane self-assembly and interfacial reaction methods were acquired [35]. The prepared membrane of a thin layer of ZIF-8/PEI hybrid membrane had a methyl blue rejection of $99.6 \%$ and flux of $33.0 \mathrm{~L} \mathrm{~m}^{-2} \mathrm{~h}^{-1} \mathrm{bar}^{-1}$.

Another form of ZIF-8 membrane was prepared, a hydrostable membrane of ZIF-8 thin film [35] containing DNA on dopamine-modified PSF membrane, and the DNA enhanced the hydrophilicity.

Another application for ZIF-8 in wastewater is to determine a highly toxic material in wastewater with high selectivity [36]. ZIF-8 - ERGO nanocomposite was synthesized and successfully utilized as a sensor for hydrazine detector in wastewater for a wide range of concentrations $(0.1 \mu \mathrm{M}-1.16 \mathrm{mM})$, reaching down to a very low detection limit, $0.96 \mathrm{ppb}$.

This study aims to prepare high-performance ZIF-8/PSF membranes in a simple phase inversion procedure which is more accessible than the procedure followed in the previously mentioned papers, understanding and explaining the effect of ZIF-8 on the PSF membrane. As a result, there is an improvement in membrane rejection, and flux noticed in the following concentrations of ZIF-8, $1.5 \%$, and 3\% in the rejection of crystal violet dye and methyl blue dye.

\section{Materials and Methods}

\subsection{Materials.}

All of the chemicals and materials utilized in this experiment were of analytical quality and were used without additional purification. Deionized (DI) water produced by the Ultrapure water system by UF, RO, Mixed bed, conductivity less than $0.055 \mu \mathrm{S} / \mathrm{cm}$ at $25^{\circ} \mathrm{C}$. Polysulfone beds (Udel P 3500 LCD MP7, MW= 77000, Mn=22000), N, N dimethylformamide (DMF), methyl blue, crystal violet, and rhodamine B were purchased from Sigma-Aldrich. Zinc nitrate hexahydrate 99\%, purchased from Tianjin Kemiou Chemical Reagent, China, Ammonia Solution max. 33\% NH3, extra pure, Scharlab, 2-methylimidazole (Hmim) purchased from Sinopharm chemical reagent Co. Ltd., China. 


\subsection{Synthesis of ZIF-8.}

This study synthesized the membrane with the same procedure as previous studies [37, 38]. First, in $3 \mathrm{gm}$ of deionized water, zinc nitrate hexahydrate $\left(\mathrm{Zn}\left(\mathrm{NO}_{3}\right)_{2} \cdot 6 \mathrm{H}_{2} \mathrm{O}\right)$ weight of $2.97 \mathrm{gm}$ was mixed till dissolution. Next, $20.75 \mathrm{~mL}$ ammonium hydroxide solution was utilized to dissolve $1.64 \mathrm{gm}$ of Hmim was; then, zinc nitrate and Hmim solutions were mixed. The solution transformed immediately into a milky suspension and was stirred for 10 minutes at room ambient temperature for crystallization to be accomplished. Finally, the sample was collected by centrifugation and washed with deionized until the $\mathrm{pH}$ value of the final product was around 7 , then dried overnight at $60{ }^{\circ} \mathrm{C}$.

\subsection{Preparation of membranes.}

Polysulfone membranes were synthesized by the phase inversion method. Membranes with various concentrations of ZIF-8 were prepared. A blank membrane was prepared for polysulfone only. PVP also was used as a pore former in some trials.

First, at a temperature of $70{ }^{\circ} \mathrm{C}$ pure PSF was dissolved in DMF, mixed with a magnetic stirrer for 8 hours. Then, various ZIF-8 concentrations were prepared by adding them to the mixture during the mixing step. The mixture was left for overnight degassing to avoid any gas bubbles inside. Later, the casting of the solution was done by a homemade casting knife on a glass sheet. The glass sheet was finally immersed in a demineralized water bath for the phase inversion. The membrane was left in demineralized water to remove the residual solvent from the membrane to be ready for testing.

Table 1. Composition of the membrane casting solution.

\begin{tabular}{l|l|l|l|l}
$\begin{array}{l}\text { Membrane } \\
\text { Number }\end{array}$ & Membrane Description & $\begin{array}{l}\text { PSF } \\
\mathbf{\%})\end{array}$ & $\begin{array}{l}\text { ZIF-8 } \\
\text { (wt\%) }\end{array}$ & $\begin{array}{l}\text { DMF } \\
\text { (wt\%) }\end{array}$ \\
\hline M1 & 16\%PSF & 16 & 0 & 84 \\
\hline M2 & 16\%PSF_0.5\%ZIF-8 & 16 & 0.5 & 83.92 \\
\hline M3 & 16\%PSF_1.0\%ZIF-8 & 16 & 1 & 83.84 \\
\hline M4 & 16\%PSF_1.5\%ZIF-8 & 16 & 1.5 & 83.76 \\
\hline M5 & 16\%PSF_2.0\%ZIF-8 & 16 & 2 & 83.68 \\
\hline M6 & 16\%PSF_3.0\%ZIF-8 & 16 & 3 & 83.52 \\
\hline M7 & 16\%PSF_5.0\%ZIF-8 & 16 & 5 & 83.2
\end{tabular}

\subsection{Characterization.}

2.4.1. Characterization by morphological studies.

XRD was used to study the structure of the prepared ZIF-8. Diffractometer system, CubiX3, Tube anode is copper, Generator Settings, $40 \mathrm{~mA}, 40 \mathrm{kV}$, Start Position [ $\left.{ }^{\circ} 2 \theta\right] 15.0025$, End Position [ ${ }^{\circ} 2 \theta$ ] 130. FTIR analysis using JASCO FT/IR 4100 spectrometer (Jasco, Easton, $\mathrm{MD}$, USA). The sample was ground and put into $\mathrm{KBr}$ disc before analysis from $400 \mathrm{~cm}^{-1}$ to $4000 \mathrm{~cm}^{-1}$.

UV spectrometer, Orion aquamate 8000 used $1 \mathrm{~cm}$ quartz cell for measuring the dye's absorbance.

The membranes were characterized by morphological analysis and permeation characteristics. The morphological characteristics were analyzed by scanning electron microscope, wavelength dispersive X-ray fluorescence (WD-XRF) Axios mAx by PANalytical, by the Netherlands. In addition, the contact angle instrument Kruss model DSA25B, Sissle drop method was used to study the hydrophilicity of the membrane. The 
contact angle depends on the angle between the surface of the membrane and the meniscus formed by the water droplet.

Scanning electron microscope (SEM) Quanta FEG250, USA, accelerating voltage $20 \mathrm{Kv}$, spot size 3.5, low vacuum mode, controlled backscattered detector was used for membrane surface and cross-section morphology. In addition, SEM was used to study topography, pore structure, and microscopic characteristics of the membranes and ZIF-8.

\subsubsection{Characterization by permeation studies.}

Stirred dead-end cell HP4750 was utilized to test the performance of the prepared membranes with $14.6 \mathrm{~cm}^{2}$ as an effective membrane area, a cell diameter of $5.1 \mathrm{~cm}^{2}$, and a processing volume of $300 \mathrm{~mL}$. This stirred cell was pressurized by a nitrogen gas cylinder. The pure water permeability of the membranes was tested at different applied pressures ranging from 1 to 5 bar. The volume flux was calculated as follow:

Flux $=$ Volume of water passed $($ Liter $) /\left(\right.$ membrane surface area $\left.\left(\mathrm{m}^{2}\right)\right) *($ time consumed to pass this quantity (hour).

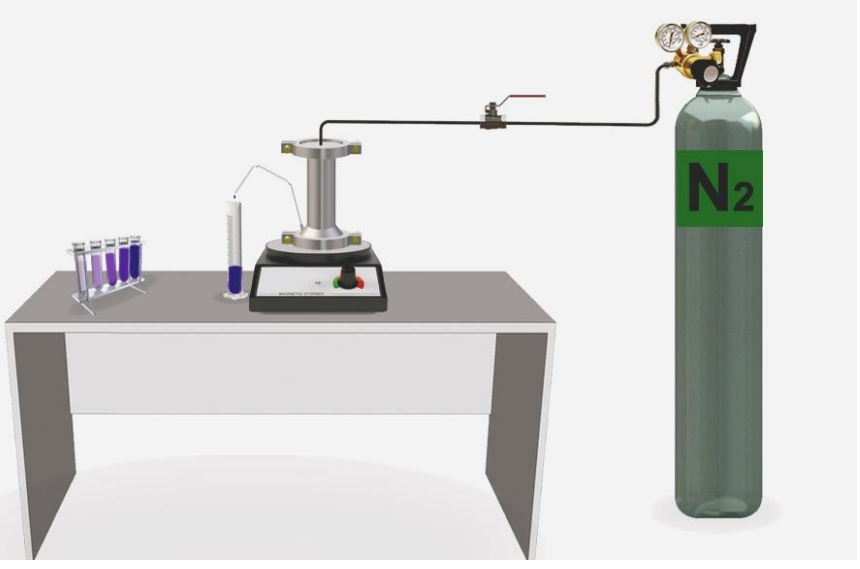

Figure 1. 3D drawing for the stirred cell permeation test system.

\section{Results and Discussion}

The characteristics and formula of the membrane were changed by changing its components, an additive which is in our case is ZIF-8. The additive concentration was the dominant factor studied within this paper to choose the proper concentration of the nanomaterial added. So, the effect of nanomaterial concentration on pure water flux and membrane rejection was studied with concentration. It was clear that pure PSF membrane has a lower water flux of $50.42 \mathrm{~L} / \mathrm{m}^{2} . \mathrm{h}$ while ZIF-8 in PSF membrane enhanced the flux to $83.65 \mathrm{~L} / \mathrm{m}^{2} . h$.

\subsection{Morphological study.}

\subsubsection{ZIF-8 Characterization}

\subsubsection{ZIF-8 Characterization by FTIR.}

FTIR and XRD were used to study the composition of the prepared nanoparticles ZIF8. We used the FTIR in the wavenumber range of 400 to $4000 \mathrm{~cm}^{-1}$ to confirm the composition of the prepared ZIF- 8 by investigating its functional groups. Imidazole stretching of the 
aromatic and aliphatic $\mathrm{C}-\mathrm{H}$, respectively, were confirmed by the peaks at $2930 \mathrm{~cm}^{-1}$ and 3134 $\mathrm{cm}^{-1} . \mathrm{C}=\mathrm{N}$ stretching mode of the 2-methyl imidazole was detected at $1583 \mathrm{~cm}^{-1}$. The $\mathrm{C}-\mathrm{N}$ stretch has been detected by the peaks in the range of $1460-1143 \mathrm{~cm}^{-1}$, and the $420 \mathrm{~cm}^{-1}$ band is assigned to the $\mathrm{Zn}-\mathrm{N}$ stretch [36]. The stretching of the ring was detected by the peaks at $1380-1583 \mathrm{~cm}^{-1}$. The ring bending in the plan is indicated by peaks in the spectral region of $952-1380 \mathrm{~cm}^{-1}$ [39].

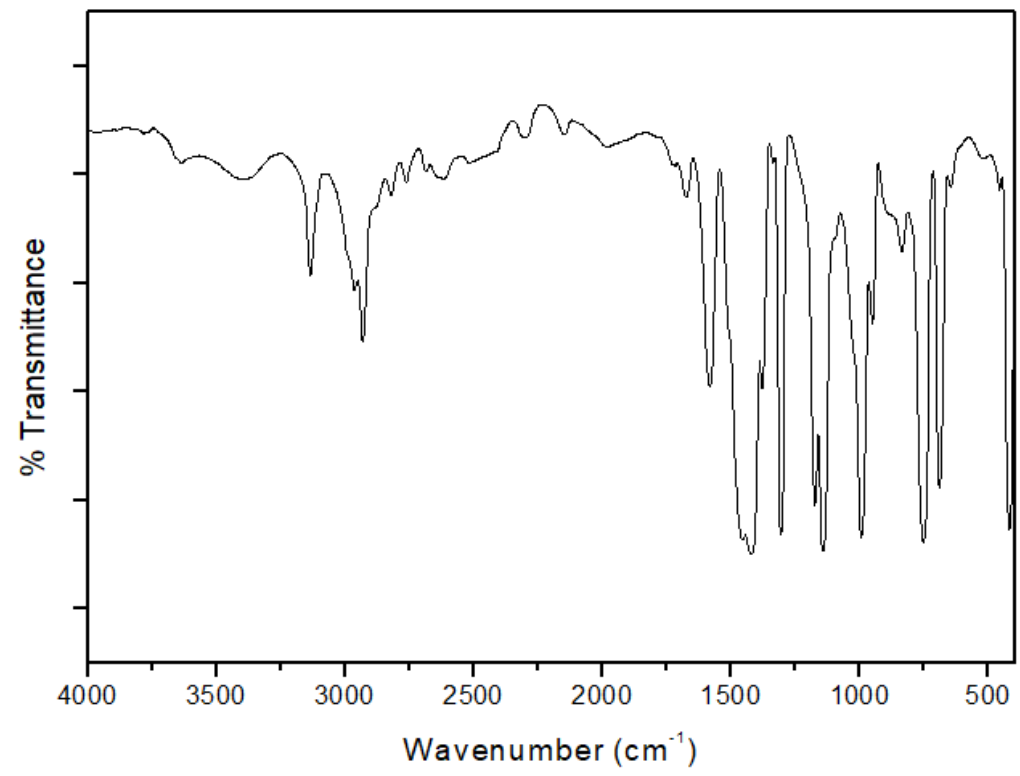

Figure 2. FTIR spectrum of the prepared ZIF-8.

\subsubsection{ZIF-8 Characterization by SEM.}

SEM was used to study the structure, physical and chemical properties. We measured some of the particles from the SEM picture of the average particle size of the prepared ZIF-8 particles was around $200 \mathrm{~nm}$.

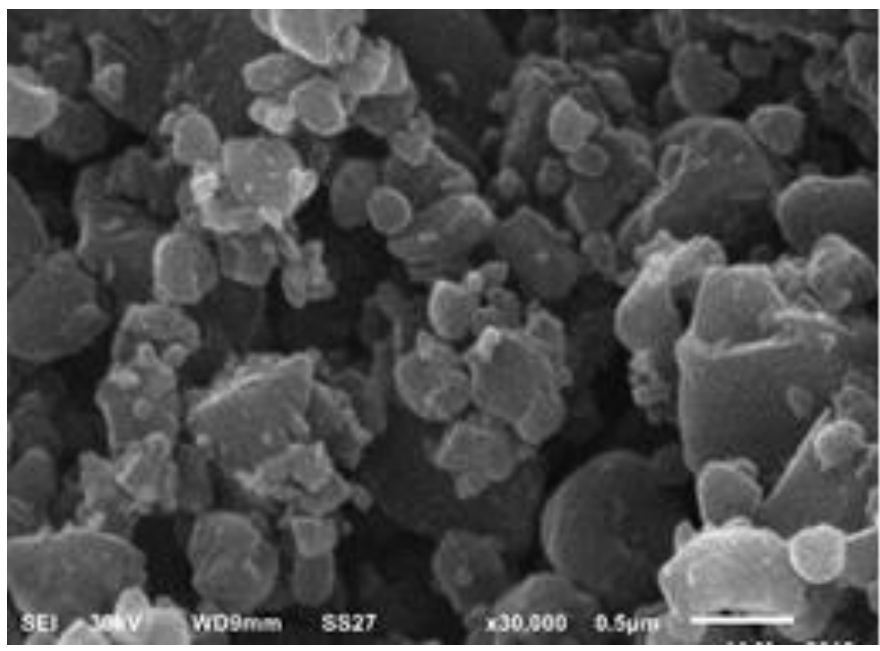

Figure 3. SEM image of the prepared ZIF-8.

\subsubsection{ZIF-8 Characterization by XRD.}

The phase of ZIF-8 was the only one existing within the prepared material, showing a highly crystalline structure.

The ZIF-8 pattern XRD as-synthesized was presented in Figure 4. It is possible to allocate the sample to ZIF-8, and no other step has been found in these samples. According to 
the XRD analysis, planes (011), (002), (112), (022), (013), and (222), respectively, correspond to the occurrence of high peaks at $2 \theta=9.94,12.29,14.28,15.91,17.35$ and $18.98^{\circ}$, This income that the prepared ZIF-8 has high crystallinity (JCPDS 00-062-1030). Calculations using Fullprof and check cell software revealed that the ZIF-8 crystal system under consideration exhibited a monoclinic crystal system with space group $\mathrm{P}_{21}$, and the lattice parameters were; a $=17.75 \AA, \mathrm{b}=12.817 \AA, \mathrm{c}=19.226 \AA, \alpha=90.0^{\circ}, \beta=104.64^{\circ}$ and $\gamma=90.0^{\circ}$. Miller indices $(h k l)$ and interplanar spacing $(d h k l)$ for ZIF-8 are recorded in Table 3. Using Scherrer formula (Eq. 1), the crystallite size nanoparticles of ZIF-8 (D, А̊) ZIF-8 was determined.

$$
\mathrm{D}=\mathrm{K} \lambda / \beta \operatorname{Cos} \theta \mathrm{B}
$$

where $\lambda=1.54 \AA$ is the $\mathrm{X}$-ray tube wavelength, $\beta$ is the peak's angular width at half its highest amplitude (full width at half-maximum) that corrects for instrumental broadening, B is the most significant factor in the Bragg diffraction peak's, and the Scherrer constant $\mathrm{K}=0.9 \AA$. Calculated from the high-intensity (002) peak, the size of crystallite for ZIF-8 was $255 \mathrm{~nm}$.

Table 2. ZIF-8 crystallographic data.

\begin{tabular}{|c|c|c|c|c|}
\hline $2 \theta_{\text {Obs. }}\left({ }^{\circ}\right)$ & $2 \theta_{\text {Calce }}\left(\left(^{\circ}\right)\right.$ & $\mathbf{d}_{h k l(O b s)}\left({ }^{\circ} \mathbf{A}\right)$ & $\begin{array}{l}\mathbf{d}_{h k l(\text { Calc. })} \\
\left({ }^{\circ} \mathbf{A}\right)\end{array}$ & $(h k l)$ \\
\hline 12.1978 & 12.1978 & 12.3136 & -0.1158 & -111 \\
\hline 14.1729 & 14.1729 & 14.2619 & -0.0890 & 111 \\
\hline 17.4991 & 17.4991 & 17.6108 & -0.1117 & 021 \\
\hline 21.5970 & 21.5970 & 21.6823 & -0.0853 & 221 \\
\hline 23.9636 & 23.9636 & 24.0667 & -0.1031 & -131 \\
\hline 25.0680 & 25.0680 & 25.1422 & -0.0742 & 131 \\
\hline 29.1220 & 29.1220 & 29.1654 & -0.0434 & 421 \\
\hline 30.0638 & 30.0638 & 30.0514 & 0.0124 & -113 \\
\hline 30.9795 & 30.9795 & 30.9910 & -0.0115 & 041 \\
\hline 31.8659 & 31.8659 & 31.8978 & -0.0319 & -241 \\
\hline 33.5901 & 33.5901 & 33.5544 & 0.0357 & 241 \\
\hline 36.0206 & 36.0206 & 36.0152 & 0.0054 & 332 \\
\hline 36.8077 & 36.8077 & 36.7118 & 0.0959 & -133 \\
\hline 37.7099 & 37.7099 & 37.7936 & -0.0837 & -712 \\
\hline 38.3415 & 38.3415 & 38.2753 & 0.0662 & 621 \\
\hline 41.2450 & 41.2450 & 41.2260 & 0.0190 & -533 \\
\hline 42.6429 & 42.6429 & 42.6040 & 0.0389 & -641 \\
\hline 43.9638 & 43.9638 & 43.8943 & 0.0695 & -443 \\
\hline 45.9710 & 45.9710 & 45.8714 & 0.0996 & -260 \\
\hline 47.2699 & 47.2699 & 47.2570 & 0.0129 & -624 \\
\hline 49.1499 & 49.1499 & 49.2526 & -0.1027 & 062 \\
\hline 64.3503 & 64.3503 & 64.3739 & -0.0236 & -573 \\
\hline 77.4669 & 77.4669 & 77.4154 & 0.0515 & 591 \\
\hline
\end{tabular}

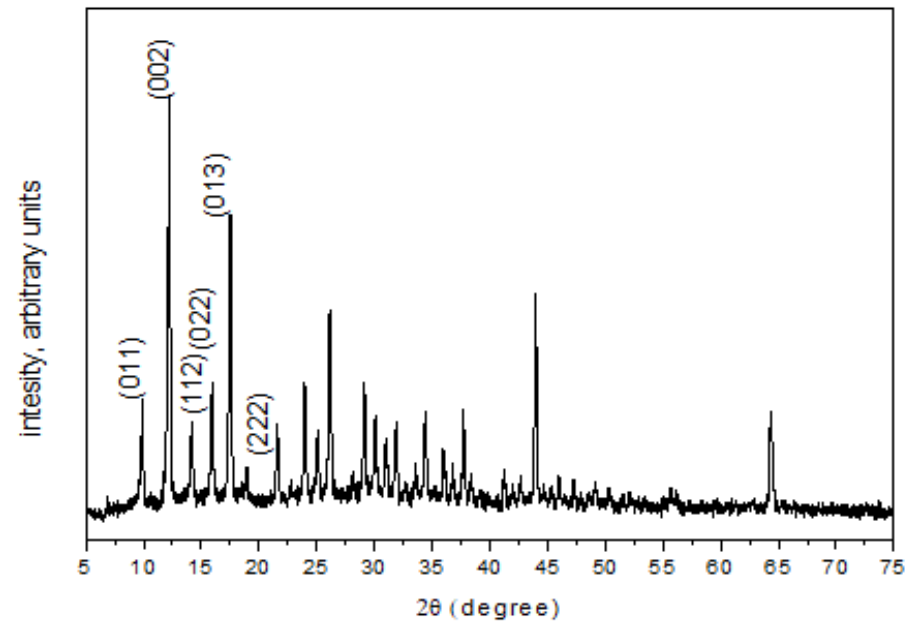

Figure 4. XRD diffractogram for ZIF-8 sample. 


\subsubsection{Membrane characterization.}

Figure 5 shows the cross-section pictures of the membranes. The membrane in the first picture of pure PSF is a spongy-like structure. By adding the nanoparticles to the membrane, the pores started to expand to be macro voids forming finger-like pores due to increasing ZIF8 concentration. ZIF-8 penetrates through the membrane polymer, enhancing the interconnectivity of the pores. The porosity started to be uniformly formed from the concentration of $1.5 \% \mathrm{ZIF}-8$, at which the finger-like pores were significant, and the pores were sponge-like. In higher concentrations, the pores existed but looked less spongy, and the pore size was getting more significant.
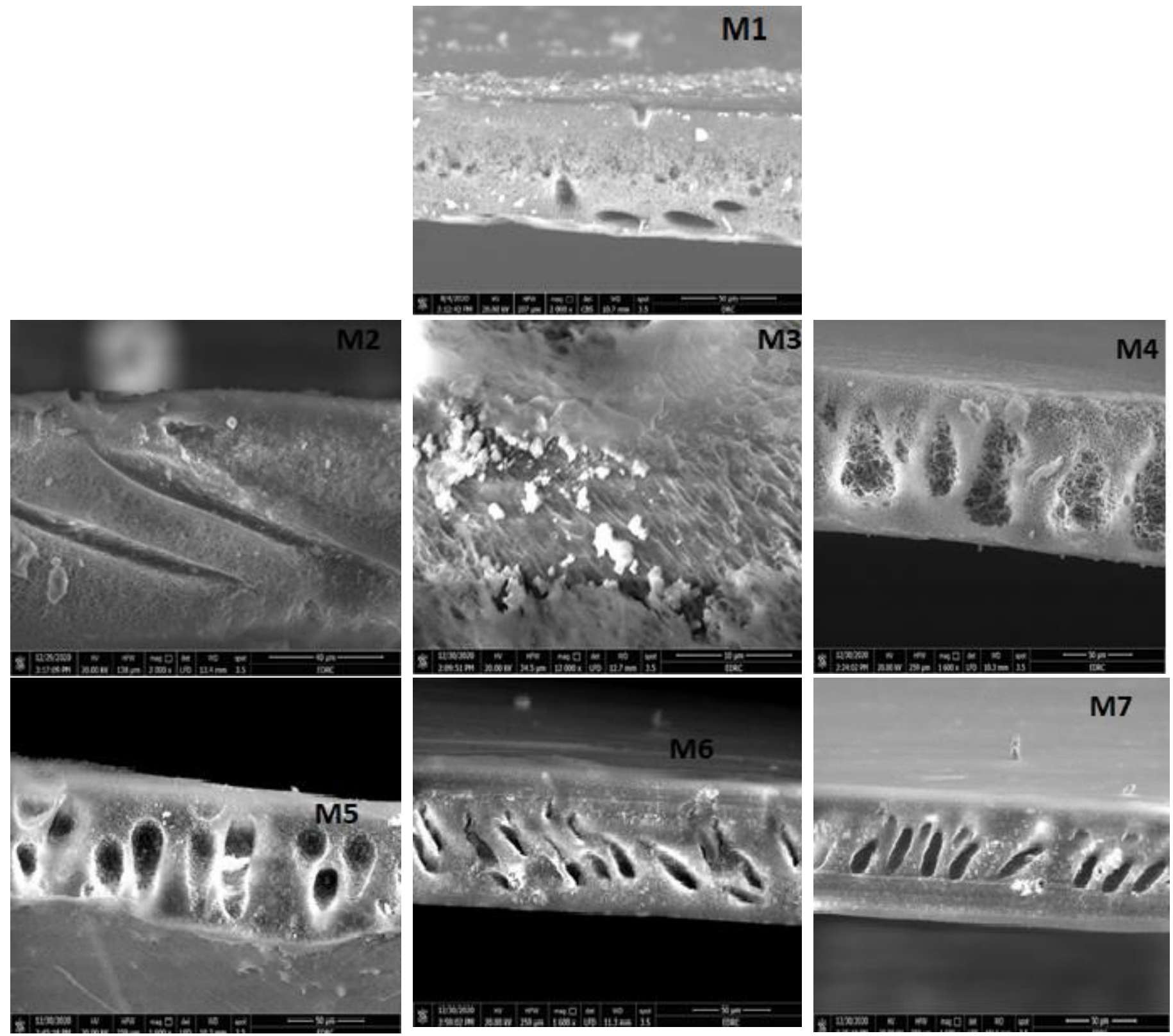

Figure 5. Cross-section SEM images for the membranes show the ZIF-8 particle size in the membrane and the pore size.

Figure 6 shows the effect of the addition of ZIF-8 into the membranes' surface and membrane porosity. ZIF-8 was found to be homogeneously distributed. The surface porosity increased by increasing the concentration of ZIF-8 compared with the pure PSF; specifically, it started to be clear as the concentration of the nano ZIF-8 concentration started to increase. 
Nanoparticles material is distributed homogeneously in the PSF polymer chain, which is apparent in SEM surface figures. The figures show that adding ZIF-8 to the casting solution improved the roughness of the PSF membrane.

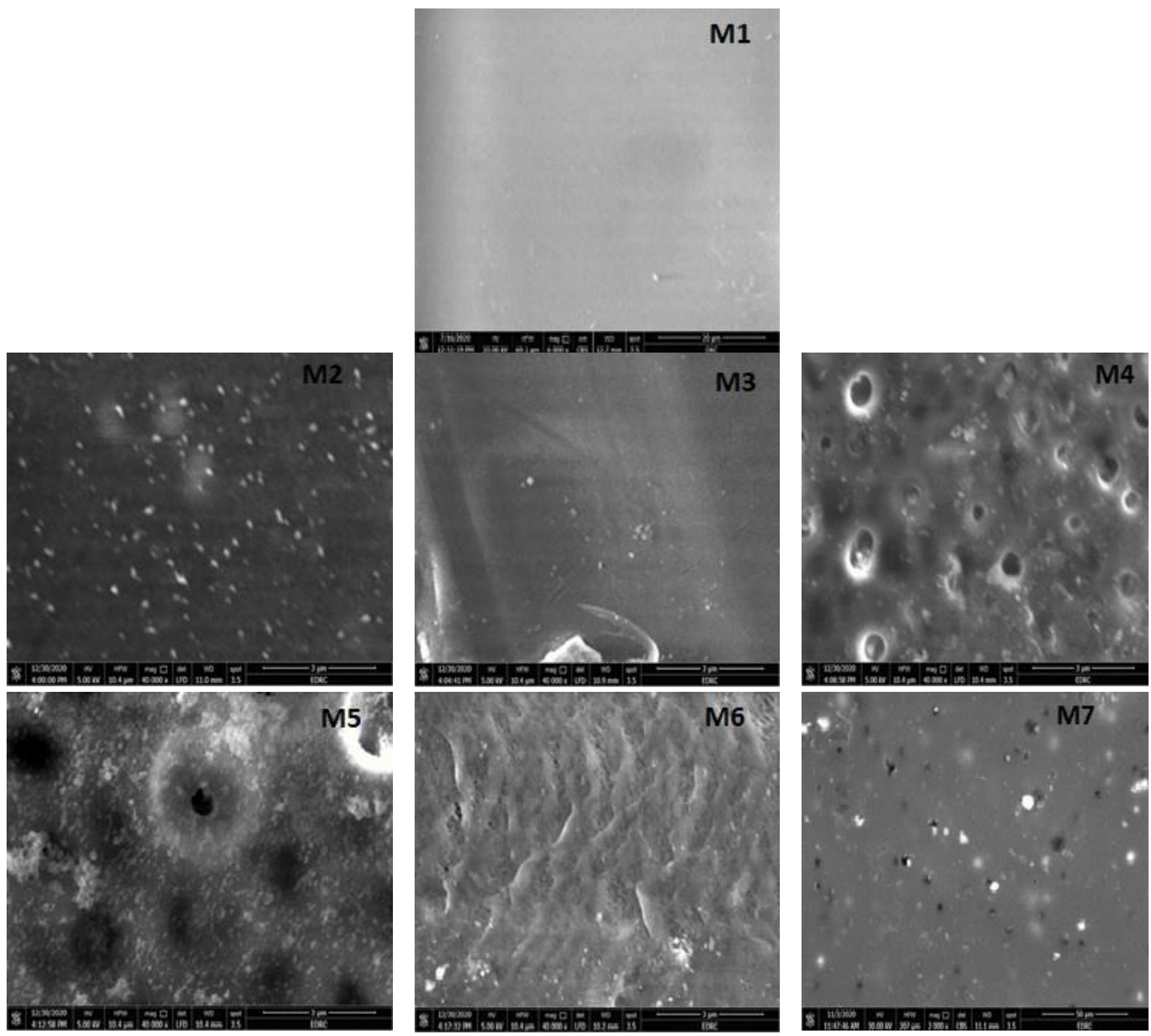

Figure 6. Surface SEM images for the membranes show the ZIF-8 particle size in the membrane and the pore size.

Wavelength dispersive X-ray fluorescence ZIF-8 was used to investigate the membranes by tracing the Zinc element to indicate the presence of ZIF-8 in the membrane. Zn $\mathrm{K}$ alpha and $\mathrm{K}$ beta peaks existed in all PSF membranes containing ZIF-8. Also, the intensity was linearly decreasing in decreasing order of ZIF-8 concentration. 


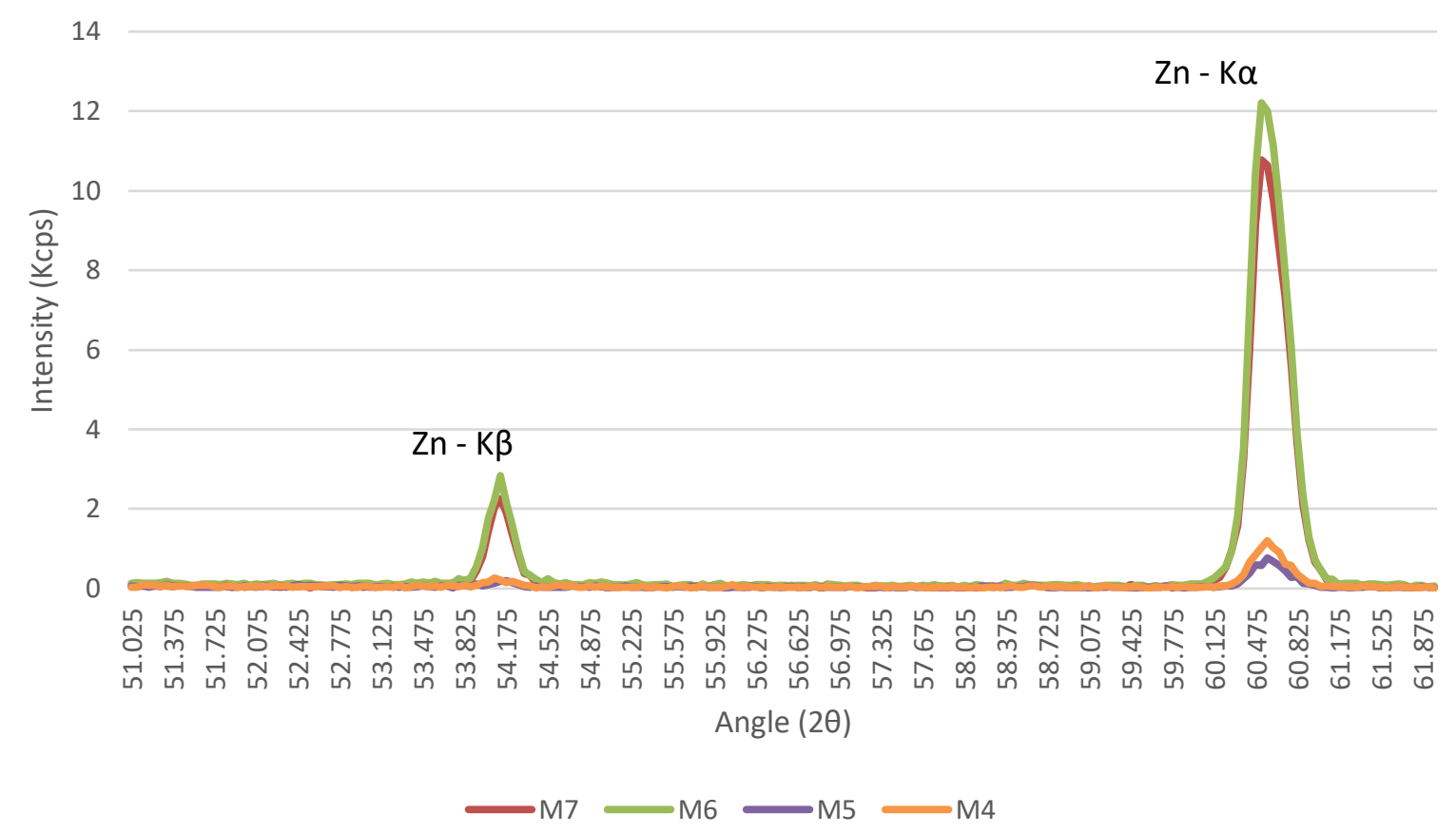

Figure 7. Elemental analysis for the membranes by WD-XRF shows the increasing intensity of the $\mathrm{Zn}$ peaks correlated with the rising concentration of ZIF-8.

The contact angle is used in many pieces of research as an indication for membrane hydrophilicity. Therefore, it was expected that adding ZIF-8 would enhance the hydrophilicity, while our measurements show a clear relationship between increasing ZIF-8 concentration and the contact angle [40].

Table 2. The membrane concentrations and contact angle of each membrane.

\begin{tabular}{l|l|l|l|l}
$\begin{array}{l}\text { Membrane } \\
\text { Number }\end{array}$ & $\begin{array}{l}\text { PSF } \\
\mathbf{\%})\end{array}$ & $\begin{array}{l}\mathbf{Z I F - 8} \\
\mathbf{( w t} \%)\end{array}$ & $\begin{array}{l}\text { DMF } \\
(\mathbf{w t} \%)\end{array}$ & $\begin{array}{l}\text { Average } \\
\text { Contact Angle }\end{array}$ \\
\hline M1 & 16 & 0 & 84 & 91.7 \\
\hline M2 & 16 & 0.5 & 83.92 & 48.87 \\
\hline M3 & 16 & 1 & 83.84 & 58.67 \\
\hline M4 & 16 & 1.5 & 83.76 & 71.25 \\
\hline M5 & 16 & 2 & 83.68 & 43.70 \\
\hline M6 & 16 & 3 & 83.52 & 53.45 \\
\hline M7 & 16 & 5 & 83.2 & 61.23
\end{tabular}

\subsection{Permeation experiment.}

Membranes were tested to see the effect of different concentrations addition of ZIF-8 on their permeation behavior. Finally, the membranes are subjected to study for rejection and permeate flux behavior.

\subsubsection{Pure water flux.}

The pure water flux test was performed at a pressure of 1 bar after compacting the membrane at 5 bar for 30 minutes. The flux average results show that the highest flux was at the membrane $1.5 \% \mathrm{ZIF}-8$.

Pure water flux of the ZIF-8/PSF membranes enhanced from $50.41 \mathrm{~L} / \mathrm{m}^{2} . \mathrm{h}$ in the pure PSF membrane to $83.65 \mathrm{~L} / \mathrm{m}^{2} . h, 57.53 \mathrm{~L} / \mathrm{m}^{2} . h$, and $70.05 \mathrm{~L} / \mathrm{m}^{2} . \mathrm{h}$, respectively for M4, M2, and M6 samples, and then declined to $47.6 \mathrm{~L} / \mathrm{m}^{2} . \mathrm{h}, 40.69 \mathrm{~L} / \mathrm{m}^{2} . \mathrm{h}$, and $38.72 \mathrm{~L} / \mathrm{m}^{2} . \mathrm{h}$ for M3, M7, and M5 samples, respectively. The permeability of water was due to the sodalite Zeolite-type structure of cavities of $1.1 \mathrm{~nm}$ and pore size of $0.34 \mathrm{~nm}[41,42]$. 
The framework of ZIF-8 has pores of the range 4.0 to $4.2 \AA$ allowing water to path through (water molecules diameter $2.8 \AA$ ). Through the membrane, channels of hydrophobic nature are formed to accelerate the transition of water molecules because of the repulsion between ZIF-8 on the channel's walls and the water molecules.

Table 3. The flux through the different prepared membranes.

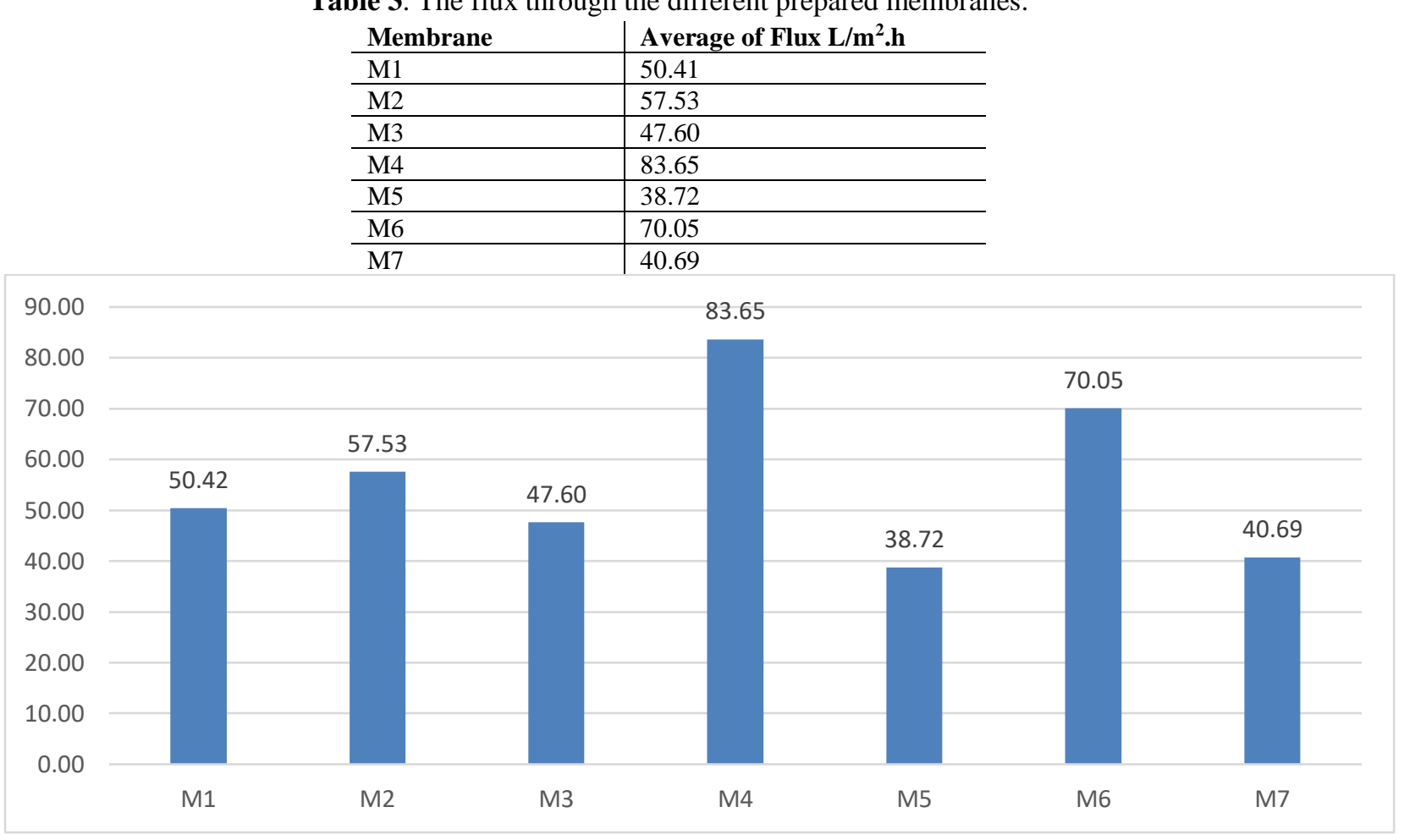

Figure 8. Pure water flux L/m².h of PSF membranes with different ZIF-8 concentrations.

Table 4. The rejection percentage of two dyes, crystal violet and methyl blue, in membranes of different ZIF-8 concentrations.

\begin{tabular}{l|lllllll}
\multicolumn{1}{l}{} & M1 & M2 & M3 & M4 & M5 & M6 & M7 \\
\hline Crystal Violet & 41.08 & 75.38 & 62.13 & 90.62 & 89.11 & 89.03 & 53.79 \\
Methyl Blue & 46.32 & 71.79 & 68.21 & 95.10 & 91.03 & 93.01 & 68.81
\end{tabular}

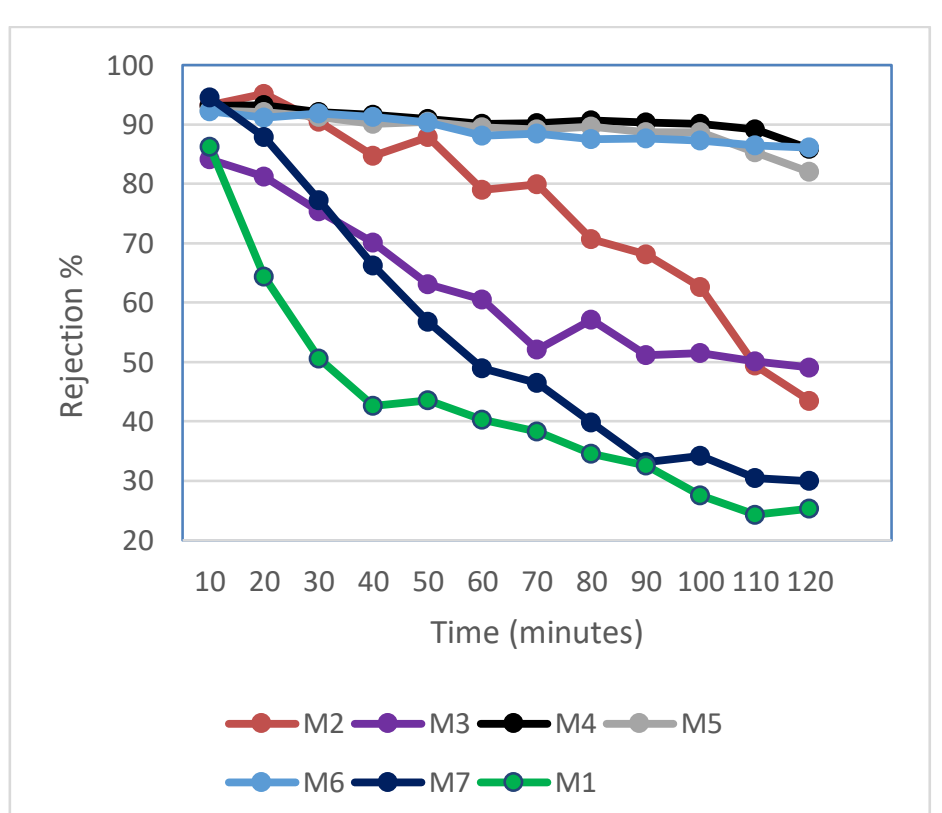

Figure 9. Performance of the prepared membranes with different ZIF-8 concentrations by rejection percentage of $60 \mathrm{mg} / \mathrm{L}$ methyl blue dye at a pressure of $100 \mathrm{kpa}$. 


\subsubsection{Dye separation evaluation.}

ZIF-8 is a highly porous material with a high potential to enhance the performance of the membrane so it can enhance membrane permeance without affecting its selectivity. ZIF-8 concentration in PSF membranes contribution on dye removal was studied by two dyes: crystal violet $(\mathrm{CV})$ and methyl blue (MB). A dead-end filtration cell under operating pressure of 100 $\mathrm{KPa}$ and the dye concentration of $10 \mathrm{mg} / \mathrm{L}$ for $\mathrm{CV}$ and $60 \mathrm{mg} / \mathrm{L}$ for MB. The ZIF-8/PSF membranes had higher rejection than the pure PSF due to the small particle size of the prepared ZIF-8, the high porosity, and the hydrophobicity of ZIF-8, which is presented in Table 4.

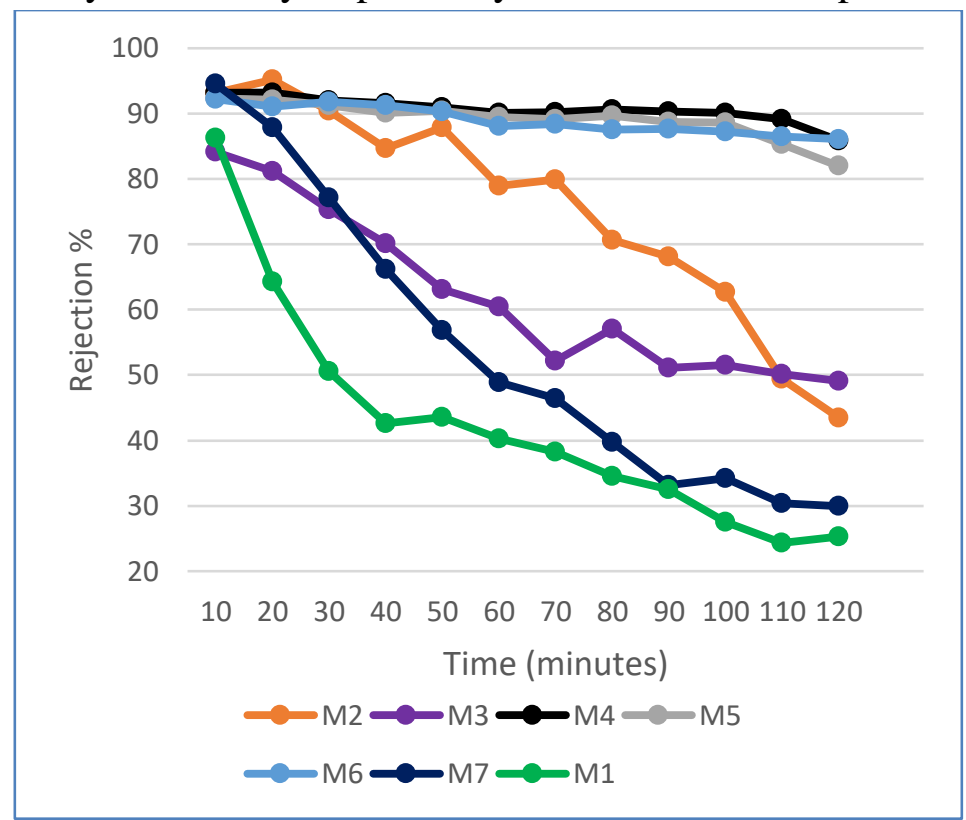

Figure 10. Performance of the prepared membranes with different ZIF-8 concentrations by rejection percentage of $10 \mathrm{mg} / \mathrm{L}$ crystal violet dye at a pressure of $100 \mathrm{kpa}$.

Table 5. The chemical formula and molecular weights of the tested dyes.

\begin{tabular}{l|l|l|}
\hline Chemical & Methyl Blue \\
Structure
\end{tabular}

Considering the membrane permeance and rejection, the optimum ZIF-8 concentration in the membrane for methyl blue and crystal violet separation was $1.5 \%$ ZIF-8. 
Table 6. Membrane performance comparison between this study and other studies using MOF as filler material.

\begin{tabular}{l|l|l|l|l|l} 
Membranes & Water flux $(\mathbf{L} / \mathbf{m} \mathbf{2 . h})$ & & $\begin{array}{l}\text { Rejection } \\
(\boldsymbol{\%})\end{array}$ & $\begin{array}{l}\text { Contact } \\
\text { angle }\left(^{\circ}\right)\end{array}$ & References \\
\hline ZIF-8/GO/PA & 40.63 & $\mathrm{MgCl}_{2}$ & 10.5 & 16.8 & {$[42]$} \\
\hline ZIF-8(hZIF-8)PSF (2.0 wt\%) & 597 & BSA & $>98$ & 62.4 & {$[43]$} \\
\hline UiO-66/GO/PES (3.0 wt\%) & 15 & Dye & $>95$ & 60.4 & {$[44]$} \\
\hline Zn/Co 74/PES & 117 & BSA & $>80$ & 49 & {$[43]$} \\
\hline TMU-5/MOF (0.1wt\%) & 182 & Powder Milk solution & $>98$ & 57.5 & {$[45]$} \\
\hline ZGO-NH/PES(1.0 wt\%) & 95.49 & BSA & $>99$ & 62.45 & {$[41]$} \\
\hline ZIF-8/PVDF & 134.56 & BSA & $>98$ & 48.2 & {$[46]$} \\
\hline PS/PEI & 30 & AO-74 & 68.5 & 80.8 & {$[46]$} \\
\hline ZIF-8/PS & & OM & 64.7 & & \\
\hline
\end{tabular}

\section{Conclusions}

ZIF-8 nanomaterial was prepared in aqueous media to be utilized in the PSF membrane. The high dispersibility of ZIF-8 was obtained after preparing ZIF-8 in nano size, around 200 $\mathrm{nm}$. Utilizing this nano-size ZIF-8 in phase inversion prepared PSF flat membrane was found to improve their performance. The prepared nanomaterial and membrane were characterized by XRD, SEM, WD-XRF, and contact angle. The characterization results confirmed the incorporation and the effect of the nanomaterial ZIF-8 into the morphology and chemical structure prepared membrane.

The pure water flux of the membrane reached the highest figures with a $1.5 \%$ concentration of ZIF-8, $83.65 \mathrm{~L} / \mathrm{m}^{2}$.h, significantly higher than PSF without ZIF-8, 50.42 $\mathrm{L} / \mathrm{m}^{2}$.h. This increase in PWF was related to the small size of the prepared ZIF-8, and its hydrophobic nature, which allowed extra pores and channels to be formed. Methyl Blue and Crystal violet dyes were utilized to study the improvement of the performance of the membrane. For methyl blue, the rejection of the dye was increased to reach the highest figure in membranes with $1.5 \%$ \& $3 \%$ concentrations of ZIF-8, $95.1 \%$, and $93 \%$, respectively.

For Crystal violet, the rejection was $90.68 \%$ and $89.01 \%$ for membranes with concentrations of $1.5 \%$ and $3 \%$ ZIF-8, respectively. From the rejection of the two dyes and the pure water flux, it is clear that $1.5 \%$ ZIF- 8 was the optimum concentration in the membrane, which resulted in the highest PWF and highest rejection for the two dyes.

\section{Funding}

This research received no external funding.

\section{Acknowledgments}

This research has no acknowledgment.

\section{Conflicts of Interest}

The authors declare no conflict of interest.

\section{References}

1. Ghaedi, M.; Ansari, A.; Habibi, M.H.; Asghari, A.R. Removal of malachite green from aqueous solution by zinc oxide nanoparticle loaded on activated carbon: Kinetics and isotherm study. Journal of Industrial and Engineering Chemistry 2014, 20, 17-28, https://doi.org/10.1016/j.jiec.2013.04.031.

2. Crini, G. Non-conventional low-cost adsorbents for dye removal: A review. Bioresource Technology 2006, 97, 1061-1085, https://doi.org/10.1016/j.biortech.2005.05.001. 
3. Kaur, H.; Bulasara, V.K.; Gupta, R.K. Influence of $\mathrm{pH}$ and temperature of dip-coating solution on the properties of cellulose acetate-ceramic composite membrane for ultrafiltration. Carbohydrate Polymers 2018 , 195, 613-621, https://doi.org/10.1016/j.carbpol.2018.04.121.

4. Lv, J.; Zhang, G.; Zhang, H.; Yang, F. Exploration of permeability and antifouling performance on modified cellulose acetate ultrafiltration membrane with cellulose nanocrystals. Carbohydrate Polymers 2017, 174, 190-199, https://doi.org/10.1016/j.carbpol.2017.06.064.

5. Liu, Y.; Huang, H.; Huo, P.; Gu, J. Exploration of zwitterionic cellulose acetate antifouling ultrafiltration membrane for bovine serum albumin (BSA) separation. Carbohydrate Polymers 2017, 165, 266-275, https://doi.org/10.1016/j.carbpol.2017.02.052.

6. Makhetha, T.A.; Moutloali, R.M. Antifouling properties of $\mathrm{Cu}(\mathrm{tpa}) @ \mathrm{GO} / \mathrm{PES}$ composite membranes and selective dye rejection. Journal of Membrane Science 2018, 554, 195-210, https://doi.org/10.1016/j.memsci.2018.03.003.

7. Sumisha, A.; Arthanareeswaran, G.; Lukka Thuyavan, Y.; Ismail, A.F.; Chakraborty, S. Treatment of laundry wastewater using polyethersulfone/polyvinylpyrollidone ultrafiltration membranes. Ecotoxicology and Environmental Safety 2015, 121, 174-179, https://doi.org/10.1016/j.ecoenv.2015.04.004.

8. Hamid, N.A.A.; Ismail, A.F.; Matsuura, T.; Zularisam, A.W.; Lau, W.J.; Yuliwati, E.; Abdullah, M.S. Morphological and separation performance study of polysulfone/titanium dioxide $\left(\mathrm{PSF} / \mathrm{TiO}_{2}\right)$ ultrafiltration membranes for humic acid removal. Desalination 2011, 273, 85-92, https://doi.org/10.1016/j.desal.2010.12.052.

9. Aryanti, P.T.P.; Khoiruddin; Wenten, I.G. Influence of Additives on Polysulfone-Based Ultrafiltration Membrane Performance during Peat Water Filtration. Journal of Water Sustainability 2013, 3, 85-96, https://doi.org/10.11912/jws.3.2.85-96.

10. Guillen, G.R.; Farrell, T.P.; Kaner, R.B.; Hoek, E.M.V. Pore-structure, hydrophilicity, and particle filtration characteristics of polyaniline-polysulfone ultrafiltration membranes. Journal of Materials Chemistry 2010, 20, 4621-4628, https://doi.org/10.1039/B925269J.

11. Zhu, F.; Zheng, Y.-M.; Zhang, B.-G.; Dai, Y.-R. A critical review on the electrospun nanofibrous membranes for the adsorption of heavy metals in water treatment. Journal of Hazardous Materials 2021, 401, 123608, doi:https://doi.org/10.1016/j.jhazmat.2020.123608.

12. Li, N.; Yang, H. Construction of natural polymeric imprinted materials and their applications in water treatment: A review. Journal of Hazardous Materials 2021, 403, 123643, https://doi.org/10.1016/j.jhazmat.2020.123643.

13. Sun, M.P.; Su, Y.L.; Mu, C.X.; Jiang, Z.Y. Improved Antifouling Property of PES Ultrafiltration Membranes Using Additive of Silica-PVP Nanocomposite. Ind. Eng. Chem. Res. 2010, 49, 790-796, https://doi.org/10.1021/ie900560e.

14. Liang, S.; Xiao, K.; Zhang, S.; Ma, Z.; Lu, P.; Wang, H.; Huang, X. A facile approach to fabrication of superhydrophilic ultrafiltration membranes with surface-tailored nanoparticles. Separation and Purification Technology 2018, 203, 251-259, https://doi.org/10.1016/j.seppur.2018.04.051.

15. Jalali, A.; Shockravi, A.; Vatanpour, V.; Hajibeygi, M. Preparation and characterization of novel microporous ultrafiltration PES membranes using synthesized hydrophilic polysulfide-amide copolymer as an additive in the casting solution. Microporous and Mesoporous Materials 2016, 228, 1-13, https://doi.org/10.1016/j.micromeso.2016.03.024.

16. Vatanpour, V.; Yekavalangi, M.E.; Safarpour, M. Preparation and characterization of nanocomposite PVDF ultrafiltration membrane embedded with nanoporous SAPO-34 to improve permeability and antifouling performance. Separation and Purification Technology 2016, 163, 300-309, https://doi.org/10.1016/j.seppur.2016.03.011.

17. Moghimifar, V.; Livari, A.E.; Raisi, A.; Aroujalian, A. Enhancing the antifouling property of polyethersulfone ultrafiltration membranes using $\mathrm{NaX}$ zeolite and titanium oxide nanoparticles. RSC Advances 2015, 5, 55964-55976, https://doi.org/10.1039/C5RA06986F.

18. Punia, P.; Bharti, M.K.; Chalia, S.; Dhar, R.; Ravelo, B.; Thakur, P.; Thakur, A. Recent advances in synthesis, characterization, and applications of nanoparticles for contaminated water treatment- A review. Ceramics International 2021, 47, 1526-1550, https://doi.org/10.1016/j.ceramint.2020.09.050.

19. Nasrollahzadeh, M.; Sajjadi, M.; Iravani, S.; Varma, R.S. Starch, cellulose, pectin, gum, alginate, chitin and chitosan derived (nano) materials for sustainable water treatment: A review. Carbohydrate Polymers 2021, 251, 116986, https://doi.org/10.1016/j.carbpol.2020.116986.

20. Chen, B.; Yang, Z.; Zhu, Y.; Xia, Y. Zeolitic imidazolate framework materials: recent progress in synthesis and applications. Journal of Materials Chemistry A 2014, 2, 16811-16831, https://doi.org/10.1039/C4TA02984D.

21. Basu, S.; Maes, M.; Cano-Odena, A.; Alaerts, L.; De Vos, D.E.; Vankelecom, I.F.J. Solvent resistant nanofiltration (SRNF) membranes based on metal-organic frameworks. Journal of Membrane Science 2009, 344, 190-198, https://doi.org/10.1016/j.memsci.2009.07.051.

22. Mai, H.D.; Rafiq, K.; Yoo, H. Nano Metal-Organic Framework-Derived Inorganic Hybrid Nanomaterials: Synthetic Strategies and Applications. Chemistry - A European Journal 2017, 23, 5631-5651, https://doi.org/10.1002/chem.201604703. 
23. Kassem, A.A.; Abdelhamid, H.N.; Fouad, D.M.; Ibrahim, S.A. Hydrogenation reduction of dyes using metalorganic framework-derived CuO@C. Microporous and Mesoporous Materials 2020, 305, 110340, https://doi.org/10.1016/j.micromeso.2020.110340.

24. Li, X.; Li, D.; Zhang, Y.; Lv, P.; Feng, Q.; Wei, Q. Encapsulation of enzyme by metal-organic framework for single-enzymatic biofuel cell-based self-powered biosensor. Nano Energy 2020, 68, 104308, https://doi.org/10.1016/j.nanoen.2019.104308.

25. Low, Z.-X.; Razmjou, A.; Wang, K.; Gray, S.; Duke, M.; Wang, H. Effect of addition of two-dimensional ZIF-L nanoflakes on the properties of polyethersulfone ultrafiltration membrane. Journal of Membrane Science 2014, 460, 9-17, https://doi.org/10.1016/j.memsci.2014.02.026.

26. Wang, L.; Fang, M.; Liu, J.; He, J.; Li, J.; Lei, J. Layer-by-Layer Fabrication of High-Performance Polyamide/ZIF-8 Nanocomposite Membrane for Nanofiltration Applications. ACS Applied Materials \& Interfaces 2015, 7, 24082-24093, https://doi.org/10.1021/acsami.5b07128.

27. Dai, H.; Yuan, X.; Jiang, L.; Wang, H.; Zhang, J.; Zhang, J.; Xiong, T. Recent advances on ZIF-8 composites for adsorption and photocatalytic wastewater pollutant removal: Fabrication, applications and perspective. Coordination Chemistry Reviews 2021, 441, 213985, https://doi.org/10.1016/j.ccr.2021.213985.

28. Li, H.; Mu, P.; Li, J.; Wang, Q. Inverse desert beetle-like ZIF-8/PAN composite nanofibrous membrane for highly efficient separation of oil-in-water emulsions. Journal of Materials Chemistry A 2021, 9, 4167-4175, https://doi.org/10.1039/D0TA08469G.

29. Abdelhamid, H.N. Biointerface between ZIF-8 and biomolecules and their applications. Biointerface Res. Appl. Chem 2021, 11, 8283-8297, https://doi.org/10.33263/BRIAC111.82838297.

30. Abdelhamid, H.N. Dye encapsulated hierarchical porous zeolitic imidazolate frameworks for carbon dioxide adsorption. Journal of Environmental Chemical Engineering 2020, 8, 104008, https://doi.org/10.1016/j.jece.2020.104008.

31. Feng, S.; Zhang, X.; Shi, D.; Wang, Z. Zeolitic imidazolate framework-8 (ZIF-8) for drug delivery: a critical review. Frontiers of Chemical Science and Engineering 2021, 15, 221-237, https://doi.org/10.1007/s11705020-1927-8.

32. Wang, X.; Wu, L.; Li, N.; Fan, Y. Sealing Tröger base/ZIF-8 mixed matrix membranes defects for improved gas separation performance. Journal of Membrane Science 2021, 636, 119582, https://doi.org/10.1016/j.memsci.2021.119582.

33. Phan, A.; Doonan, C.J.; Uribe-Romo, F.J.; Knobler, C.B.; O'Keeffe, M.; Yaghi, O.M. Synthesis, Structure, and Carbon Dioxide Capture Properties of Zeolitic Imidazolate Frameworks. Accounts of Chemical Research 2010, 43, 58-67, https://doi.org/10.1021/ar900116g.

34. Karimi, A.; Khataee, A.; Safarpour, M.; Vatanpour, V. Development of mixed matrix ZIF-8/polyvinylidene fluoride membrane with improved performance in solvent resistant nanofiltration. Separation and Purification Technology 2020, 237, 116358, https://doi.org/10.1016/j.seppur.2019.116358.

35. Yang, L.; Wang, Z.; Zhang, J. Zeolite imidazolate framework hybrid nanofiltration (NF) membranes with enhanced permselectivity for dye removal. Journal of Membrane Science 2017, 532, 76-86, https://doi.org/10.1016/j.memsci.2017.03.014.

36. Xie, J.; Yang, H.; Wang, X.; Gao, F. ZIF-8/electro-reduced graphene oxide nanocomposite for highly electrocatalytic oxidation of hydrazine in industrial wastewater. Microchemical Journal 2021, 168, 106521, https://doi.org/10.1016/j.microc.2021.106521.

37. Feng, Y.; Li, Y.; Xu, M.; Liu, S.; Yao, J. Fast adsorption of methyl blue on zeolitic imidazolate framework8 and its adsorption mechanism. RSC Advances 2016, 6, 109608-109612, https://doi.org/10.1039/C6RA23870J.

38. Hassan, N.; Shahat, A.; El-Didamony, A.; El-Desouky, M.G.; El-Bindary, A.A. Equilibrium, Kinetic and Thermodynamic studies of adsorption of cationic dyes from aqueous solution using ZIF-8. Moroccan Journal of Chemistry 2020, 8, 627-636, https://doi.org/10.48317/IMIST.PRSM/morjchem-v8i3.21127.

39. Hu, Y.; Kazemian, H.; Rohani, S.; Huang, Y.; Song, Y. In situ high pressure study of ZIF-8 by FTIR spectroscopy. Chemical Communications 2011, 47, 12694-12696, https://doi.org/10.1039/c1cc15525c.

40. Ibrahim, N.A.; Wirzal, M.D.H.; Nordin, N.A.H.; Abd Halim, N.S. Development of Polyvinylidene fluoride (PVDF)-ZIF-8 Membrane for Wastewater Treatment. In IOP Conference Series: Earth and Environmental Science 2018, 140, 012021, http://dx.doi.org/10.1088/1755-1315/140/1/012021.

41. Gholami, F.; Zinadini, S.; Zinatizadeh, A.A.; Abbasi, A.R. TMU-5 metal-organic frameworks (MOFs) as a novel nanofiller for flux increment and fouling mitigation in PES ultrafiltration membrane. Separation and Purification Technology 2018, 194, 272-280, https://doi.org/10.1016/j.seppur.2017.11.054.

42. Mai, H.D.; Rafiq, K.; Yoo, A. Nano Metal-Organic Framework-Derived Inorganic Hybrid Nanomaterials: Synthetic Strategies and Applications. Chemistry: A European Journal 2017, 23, 5631-5651, https://doi.org/10.1002/chem.201604703.

43. Wang, J.; Wang, Y.; Zhang, Y.; Uliana, A.; Zhu, J.; Liu, J.; Van der Bruggen, B. Zeolitic Imidazolate Framework/Graphene Oxide Hybrid Nanosheets Functionalized Thin Film Nanocomposite Membrane for Enhanced Antimicrobial Performance. ACS Applied Materials \& Interfaces 2016, 8, 25508-25519, https://doi.org/10.1021/acsami.6b06992. 
44. Sun, H.; Tang, B.; Wu, P. Hydrophilic hollow zeolitic imidazolate framework-8 modified ultrafiltration membranes with significantly enhanced water separation properties. Journal of Membrane Science 2018, 551, 283-293, https://doi.org/10.1016/j.memsci.2018.01.053.

45. Escobar, I.C.; Van Der Bruggen, B. Microfiltration and ultrafiltration membrane science and technology. Journal of Applied Polymer Science 2015, 132, https://doi.org/10.1002/app.42002.

46. Ahmad, N.; Samavati, A.; Nordin, N.A.H.M.; Jaafar, J.; Ismail, A.F.; Malek, N.A.N.N. Enhanced performance and antibacterial properties of amine-functionalized ZIF-8-decorated GO for ultrafiltration membrane. Separation and Purification Technology 2020, 239, 116554 , https://doi.org/10.1016/j.seppur.2020.116554. 